Henning Kroll* and Peter Neuhäusler

\title{
Recent Trends of Regional Development in China - Technological Portfolios and Economic Growth
}

https://doi.org/10.1515/zfw-2018-0032

Received: November 29, 2018; accepted May 9, 2019

\begin{abstract}
This paper analyses recent patterns and trends of technological development in Chinese provinces. It reflects on characteristic distinctions between these regions' portfolios of technological activity as well as the local matches between scientific, technological and economic efforts within them. Building on both theoretical and country specific literature, it suggests that, in China, the internal structure of technological activities might play a lesser role for economic development than in established market economies while their external embeddedness could be more important. Based on a comprehensive dataset, it identifies characteristic profiles and pathways of development among China's provinces. With a view to those, its findings suggest a continued relevance of existing legacies but, equally, newly emerging industrial dynamism. While related variety is now present in many leading regions, the local match between technological and economic activities remains the most relevant discriminator between already well-developed provinces and those catching up with the leading group.
\end{abstract}

Keywords: China, patenting, relatedness, technological portfolio, transformation.

\section{Introduction}

In recent years, China developed from a purely manufacturing to a more and more innovation-driven economy. Consequently, research, technological development and industrial upgrading - issues long central in established

\footnotetext{
*Corresponding Author: Henning Kroll, Competence Center Innovation and Knowledge Economy, Fraunhofer Institute for Systems and Innovation Research, Breslauer Strasse 48, 76139 Karlsruhe, Germany, e-mail: henning.kroll@isi.fraunhofer.de; Leibniz Universität Hannover, Institute of Economic and Cultural Geography, Schneiderberg 50, 30167 Hannover, Germany Peter Neuhäusler, Competence Center Innovation and Knowledge Economy, Fraunhofer Institute for Systems and Innovation Research, Breslauer Strasse 48, 76139 Karlsruhe, Germany, e-mail: peter.neuhaeusler@isi.fraunhofer.de; Technische Universität Berlin, Chair of Innovation Economics, Marchstraße 23, 10587 Berlin, Germany
}

market economies - have gained increasing relevance for the study of China's geographies of regional development (Liu et al. 2018; Kroll and Frietsch 2014). To understand these geographies during the early years of China's economic rise, it may have been sufficient to differentiate regions by their overall level of technological activity (Liu and White 2001; Fan 1995). Since then, however, the variety of regional innovation ecosystems has increased so that it has become more and more necessary to understand not only the mere presence but also the internal structure of regions' technological activities (which will in the following be referred to as technological portfolios) - as well as their positioning with regard to both the surrounding science system and the local economy (Liefner and Wei 2014).

With regard to the former, various studies on established market economies have found that the internal structure of regions' technological portfolios influences the availability of options for industrial path development and thus economic dynamics (Frenken et al. 2007; Isaksen and Trippl 2016; Grillitsch et al. 2018). With China's continued rise as an innovation nation, it is therefore very likely that structural aspects of technological portfolios, like related and unrelated variety, will become relevant discriminators between regions' economic development. From a product space perspective, this has been demonstrated to hold worldwide at country level (Hidalgo et al., 2007). However, this paper follows Content and Frenken's (2016) suggestion in exploring a different dimension - the technological space - with potentially different implications. Moreover, China as a country bears a very distinct legacy of past technological development based on both upgrading centers of export-driven industries ( $\mathrm{Fu}$ et al. 2012; $\mathrm{Si}$ et al. 2013; Liefner and Wei 2014) and early metropolitan 'islands' in which domestic innovation was supported and 'built' in a very focused manner in particular sectors (Fan and Chen 2014; Kroll and Liefner 2008; Segal 2003).

With regard to the latter, China's scientific system long struggled with typical remnants of planned economy governance (Radosevic 1998; Gu 1999; Liu and White 2001) that lead to a persistent disconnect between scientific, technological and economic activities in many regions (Liu et al., 2018; Kroll and Frietsch, 2014). Initially, this disconnect was often particularly strong in the most dynamic centers of development due to the strong export-orienta- 
tion of technology-oriented industries (Kroll and Schiller 2010; Kroll and Frietsch 2014) and the transformation of the national research system towards one oriented at the needs of industry remained a slow and gradual process (Liu and White 2001; Liu and Jiang 2001). On the one hand, all this made the mutual dynamization of technological and economic dynamisms at a regional level notably less natural than in established market economies, putting in question any significant impact of specific internal alignments within technological portfolios. On the other hand, certain Chinese regions have always featured better-integrated innovation systems than others (Leydesdorff and Zeng 2001; Liefner 2014) so that a regional lack of connectivity could never be considered an all-encompassing norm. Moreover, science-industry relations will have improved in the context of the widespread technological catch-up in various provinces and the related shift in China's overall geographies of innovative development (Kroll 2016; Liu et al. 2018).

In general terms, both the internal structure and the embeddedness of regional technological portfolios have in recent years been highlighted in the Chinese academic debate (He et al. 2018; He and Zhu 2018) and studied at the level of provincial or municipal case studies (Fu et al. 2012; Si et al. 2013; Guo and He 2017). In parallel, some Chinese scholars investigated industrial variety at country level, seeking to better understand localized agglomeration dynamics (Guo et al., 2015; He et al., 2015; Guo \& He, 2017). and others took up related aspects in their rankings of provinces (Liu et al. 2018). With the partial exception of He et al. (2018), however, no comprehensive quantitative assessment has so far been made available on the internal composition of technological portfolios and their localised matches with parallel activities in science and the 'real economy'. Hence, it has not been possible to identify which of the abovementioned aspects of technological portfolios are associated with other aspects of regions' economic structure and - most importantly - their economic success.

Against this background, this paper aims to contribute by establishing a first, comprehensive basis to analyze regional technological portfolios in China in a quantitative manner. To that end, it will draw on diverse sources of information - from patent databases to bibliometric information to Chinese industrial statistics.

Subesequently, it will first analyze this data from a structural perspective, seeking to identify groups of provinces that display specific characteristics with a view to the character and two-sided embeddedness of their technological portfolios.
Second, it will identify characteristics changes in technological portfolios' structure and embeddedness that - in recent years - went along with diverse provinces' moving up the ladder of techno-economic capacity.

Thus, it will establish fundamental insights into the overall systems' architecture and dynamics of change that remain needed before future studies can explore causal relations between specific factors in more depth and detail.

\section{Concept}

Since the early 1990 s, a broad stream of academic contributions has developed the notion of regional innovation systems, in which the generation of technologies in localized interaction plays a central role alongside scientific activities, economic activities, and specific institutions (Cooke 1992; Cooke et al. 1998). In line with general tenets of innovation system research (Freeman 1987; Lundvall 1992; Edquist 1997), technological development is in this context considered as one constitutive component of a complex, iterative and in many aspects recursive process of conceiving and introducing new solutions (Kline and Rosenberg 1986). While this assumes intricate relations between scientific research, technological development, and economic value creation, these can never be conceived of as linear.

While focusing on regional manifestations as a central object of study, the regional innovation system approach emphasizes the crucial role of interregional exchanges of knowledge, services and goods (Asheim 2012; Asheim and Gertler 2005; Bathelt et al. 2004) as well as interregional networks of control in global value chains (Coe and Yeung 2015; Yeung 2009; Asheim and Coenen 2006). In a globalized economy, different aspects of proximity matter for innovators as well as for other economic actors (Boschma 2005) so that it must be considered the exception rather than the rule if processes of innovation-driven development are contained within the limits of administrative regions (Asheim and Isaksen 2002; Markusen 1996). That notwithstanding, institutions and conventions within this multi-scalar system (Boschma 2017) are not least shaped at the regional level, where they provide a particular anchoring ground for various relevant developments - or the lack thereof.

Against this general background, localized path dependencies and techno-industrial trajectories have constituted a central subject of interest in regional sciences for decades (Martin and Sunley 2006; David et al. 1998; Storper and Walker 1989). More recently, a substantial amount of research has been invested into the role that 


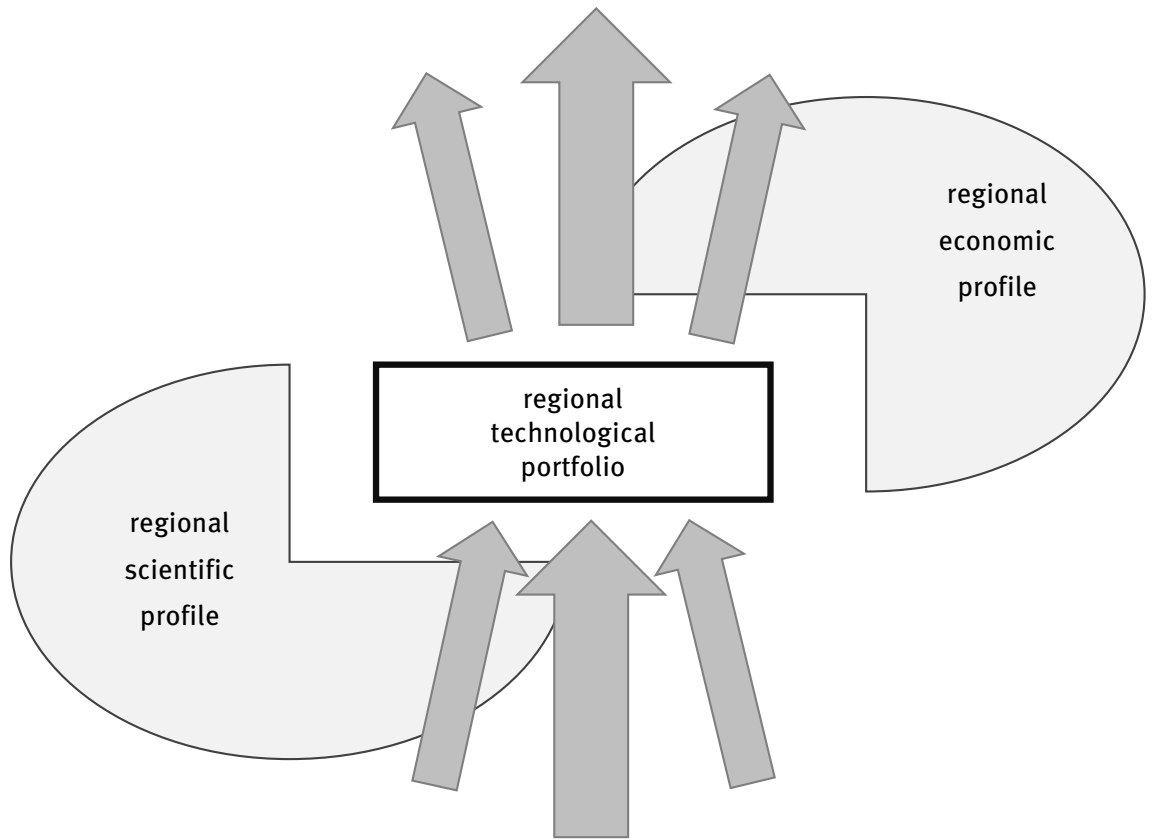

Figure 1: Regional Technological Profiles in Context.

Source: own analysis. the internal composition of regional industrial, product, and - to a still lesser extent - technological portfolios plays in this context (Content and Frenken 2016; Neffke et al. 2011; Frenken and Boschma 2007). In a majority of these studies, the concepts of 'related variety', 'unrelated variety' and similar measures of coherence have come to occupy center stage (Frenken et al. 2007; Hidalgo et al., 2007). Despite all limits to the localization of innovation processes, it has clearly been shown that the local presence of certain technological portfolios is more conducive to new industrial path creation or path renewal than others (Isaksen and Trippl 2016; Isaksen 2015).

At the same time, the intra-regional connectedness of localized innovation systems is receiving renewed attention. While the discussion had slightly subsided since its inception in the late 1990 s (e.g. Markusen, 1996, Cooke et al. 1998) the recent smart specialization debate (Foray 2014) reinvigorated reflections on the desirability of intravs. interregional connectivity and the necessary degree of local embeddedness that processes of innovation and industrial value creation require (Coe and Yeung 2015; Asheim 2012; Bathelt et al. 2004). Quite unanimously, most authors agree that a certain degree of local anchoring and match between scientific, technological and economic capacities is a desirable precondition for regional development (Asheim et al. 2016; Asheim and Gertler 2005). Without some sort of regional nexus, most achievements of local innovation efforts will materialize elsewhere or they will themselves remain dependent on external inputs (Capello and Kroll 2016; Foray 2014).
When conducting studies on China, it is therefore important to acknowledge that, as an emerging economy, this nation has been subject to different types of agency than are considered central for regional (path) development in established market economies (Boschma et al., 2017). More precisely, China has more strongly been subject to external corporate control (Coe and Yeung 2015; Liefner and Wei 2014) and its domestic policy makers pursued much more targeted development strategies (Barbieri et al. 2012; Kroll and Liefner 2008; Segal 2003). In this environment, regions' technological portfolios will to a lesser extent have been a function of gradual economic evolution than a result of dynamic, often externally triggered and financed growth - regardless of whether "external" refers to past foreign investment or central government decisions (Liefner and Wei 2014). Furthermore, China's geographies of innovation continue to reflect the legacy of older, pre-opening up industrial structures that were primarily established "according to plan" rather than based on internal economic dynamics. Up to today, these provide a persistent, if diminishing factor of China's economic geography (Liu et al. 2018; Kroll 2016; Liu and White 2001; Fan 1995). More recent studies, however, suggest that with China's reaching the global innovation frontier since the mid-2010 s, new mechanisms and determinants of technology-driven growth begin to play an increasing role, among them not least localized related variety (He et al. 2018; He and Zhu 2018; Guo and He 2017).

Against this background, there is generic conceptual value added in extending the discussion on regional tech- 
nological portfolios to China, where, diverse conceptual approaches are known to not only yield different findings but also in substance fail to explain observed processes of regional development (Liefner 2014). In short, existing findings on the role of regional technological portfolios may - explicitly or implicitly - have relied on assumptions on an 'average' regional innovation system's set-up which - in China - simply do not apply. With a view to regional technological portfolios' role in and match with regional innovation systems, therefore, it seems likely that different economic trajectories both recent and distant (Kroll 2016; Leydesdorff and Zeng 2001; Fan 1995) should have given rise to distinct patterns of regional technological relatedness and two-sided embeddedness

Currently, however, no systematic, indicator-based account is available on the central issue of which specific types of regional technological portfolios are common in China and how their overall distribution relates to that country's overall process of economic development as well as the dynamically shifting architecture of its national innovation system. In light of the above said, moreover, it not only China's general surge in innovation potential that makes this paper's stocktaking of nationally specific particularly configurations of regional innovation systems worthy of analysis. More importantly, it is that such an analysis under different conditions may help us to more generically grasp (related) variety's potential role as a contingent component in diverse processes of techno-economic development - of which, in established market economies, we can usually only witness a few, specific variants.

Against this background, this paper will document China's regions specific characteristics with a view to technological portfolios. In parallel, it takes into account the degree of 'upstream' and 'downstream' embeddedness of a region's technological activities into its scientific system on the one hand and into its local industrial structure on the other. Subsequently, it spells out in detail which of these aspects enable us to differentiate best between specific types of regional ecosystems that follow different pathways of development, and the economic success associated with that.

Against this background, it puts forward three central research questions.

RQ1: In which way do Chines regions form groups with characteristically distinct technological portfolios - regarding both their internal structure and their two-sided match with other local activities in science and industry?

RQ2: With respect to which other characteristics do these groups of regions differ? Which perform more dynamically regarding economic development and growth - and how do these findings relate to existing literature on China?
RQ3: How many provinces have recently moved from one type of group to another? In case the latter stands for economic success: which characteristic changes in technological portfolios (or their embedding) have accompanied that move?

By adressing these specific, empirical questions it will gather insights that enable conclusions on the more general conceptual issues outlined above.

\section{Data and Method}

\subsection{Approach, Dataset and Method}

The spatial level of analysis chosen for this study are China's 31 provinces, autonomous regions, and municipalities under central administration (excluding Hong Kong and Macao). This decision was taken not only because data suorces are more reliable at the provincial level than at the municipal one (Plekhanov 2017) but, more importantly, because neither technological coherence nor the degree of fit between scientific, technological and economic capacities can conceptually be meaningfully considered at a parochial level. Most of China's provinces, in contrast, surpass smaller European nations with regard to surface area, population and economic value creation, forming natural, systemic units of analysis with independent economic dynamics and notable institutional differences (within the limits common in China).

To address the three central research questions stated above, this paper will develop a detailed cluster analysis. This analysis seeks to assign China's provinces and equivalent regions to groups sharing similar characteristics with a view to their technological portfolio and that portfolios upstream and downstream embeddedness into scientific and industrial activities in the surrounding region.

With a view to data, the following analyses are based on a 2007-2015 panel dataset, drawing on SIPO patent data (retrieved from the "EPO Worldwide Patent Statistical Database”, PATSTAT), publication data retrieved from Elsevier's SCOPUS database as well as official statistics on the Chinese economy that were compiled from diverse national and provincial sources. More precisely, the dataset was compiled based on a number of differentiated queries to relational databases as well as a detailed review of various national and provincial level yearbooks and online publications of national and regional bureaus of statistics. In regionalizing SIPO patents, the authors received valuable support by the National Library of the Chinese Academy of Sciences. 
Technically, the cluster analysis was conducted using SPSS' centroid-based clustering algorithm (k-means clustering; the number of clusters is fixed to $\mathrm{x}$ clusters and squared distances from the cluster are used to assign the provinces to a cluster), following a z-standardization of all relevant variables. Based on earlier findings in the literature (Kroll, 2016), the number of supra-regional clusters was initially set to five and then increased gradually. Up until seven clusters, further differentiation yielded additional relevant sub-groups. Beyond, sub-groups became fragmented, and the assignment of regions to them increasingly became unstable and hard to interpret. Hence, the analysis was specified for seven clusters. As all calculations are based on this panel dataset, each province or equivalent area is treated separately in its subsequent, annual manifestations from 2007-2015. Throughout the study period, it can therefore fall into different functional categories of regions (clusters).

\subsection{Variables}

Based on the framework of reference provided in the conceptual section, this paper proposes four core measures for the later cluster analysis, drawing on existing findings with a view to relevant elements of local technological portfolios.

First, it calculates commonly used measures of technological variety (related variety (RV), unrelated variety (UV)) for all 31 Chinese provinces and equivalent territories, drawing on closeness in the IPC taxonomy as an indicator of technological closeness. Second, it introduces an adapted version of the 'LOS-Index' (Los, 2000) that provides a measure of technological coherence anchored in de facto patterns of technological collaboration independently from existing taxonomies. Third, it measures regional matches between scientific and technological activities through a cosine similarity measure of fit between scientific and technological outputs across fields. Equally, it measures regional matches between technological and economic activities through a cosine similarity measure of fit between technological and economic outputs across fields.

Indices for unrelated as well as related variety in technological terms were calculated based on PATSTAT data. In this specific case, technological 'unrelated variety' is defined as variety at the level of the eight main sections of the International Patent Classification (IPC) ranging from A-H (1-digit categories) whereas technological 'related variety' is defined as variety at the level of IPC 3-level sub-classes (e.g. A01, B05). ${ }^{1}$ On that basis, both indices were calculated according to the standard entropy formula proposed by Frenken et al. (2007) listed below.

$$
U V=\sum_{g=1}^{G} P_{g} \log _{2}\left(\frac{1}{P_{g}}\right)
$$

$$
R V=\sum_{g=1}^{G} P_{g} H_{g} \text { where }
$$

$$
H_{g}=\sum_{i \in S_{g}} \frac{p_{i}}{P_{g}} \log _{2}\left(\frac{1}{p_{i} / P_{g}}\right)
$$

In an alternative approach, the LOS-Index bases the assessment of technological coherence on observable patterns of collaboration rather than assumptions of closeness derived from existing taxonomies. While the original LOS-Index (Los, 2000) is calculated based on sectors' sourcing of inputs, the adapted, technological LOS-Index proposed here is based on co-patenting. As an overall framework of reference, we establish a matrix of co-patenting between all IPC 3-digit classes at world level for transnational patents (Frietsch and Schmoch 2010), thus documenting a general, worldwide co-occurrence of technologies in patent documents. We deliberately chose a country-independent measure here to generate a benchmark independent of country idiosyncracies. To account for different levels of patenting in different classes, the number of co-patents is normalized by the product of applications in either of the concerned classes, i.e. its theoretical upper limit. For the purpose of designing the final index, the respective values are then divided by the highest value to attain values between 0 and 1 , as in the original LOS-Index (Los, 2000). Different from the original LOS-Index, however, the sum for all $\mathrm{si}_{\mathrm{i}}$ need not by 1 for each $j$, so that the index can become smaller than $1 / n$. In addition, there can be missing cells, requiring that cases in which $\mathrm{s}_{\mathrm{ik}}{ }^{\star} \mathrm{s}_{\mathrm{jk}}$ would be zero are omitted. In the end, high LOS-Index values indicate coherence whereas low values indicate diversity.

$$
\operatorname{Los}_{k}=\frac{\sum_{i=1}^{n} \sum_{j=1}^{n}\left(s_{i k}{ }^{\star} s_{j k}{ }^{\star} a_{i j}\right)}{\sum_{i=1}^{n} \sum_{j=1}^{n}\left(s_{i k}{ }^{\star} s_{j k}\right)}
$$

The similarity index between regional scientific and technological capacities is calculated as the cosine similarity

1 The IPC is designed hierarchically, from very broad sections at the 1-digit level, to a very fine-grained 8-digit level 
Table 1: Descriptive Statistics for Main Variables.

\begin{tabular}{|c|c|c|c|c|c|}
\hline & Obs & Mean & Std. Dev. & Min & Max \\
\hline \multicolumn{6}{|l|}{ main dependent variables } \\
\hline unrelated variety & 279 & 2.583 & 0.260 & 0.993 & 2.841 \\
\hline related variety & 279 & 2.627 & 0.253 & 1.650 & 2.968 \\
\hline LOS-Index (adj.) & 279 & 0.005 & 0.002 & 0.003 & 0.015 \\
\hline cos-sim sci-tech & 279 & 0.746 & 0.106 & 0.309 & 0.904 \\
\hline cos-sim tech-ind & 279 & 0.517 & 0.187 & 0.167 & 0.940 \\
\hline \multicolumn{6}{|l|}{ control variables } \\
\hline GDP & 217 & 18,150 & 14,798 & 441 & 72,813 \\
\hline share industry in local GDP & 217 & 0.470 & 0.082 & 0.197 & 0.590 \\
\hline relation export / GDP & 217 & 220.4 & 257.1 & 10.7 & 1,177 \\
\hline relation foreign inv. / GDP & 217 & 0.021 & 0.023 & 0.003 & 0.140 \\
\hline graduates per population & 217 & 47 & 15 & 21 & 89 \\
\hline relation technical market / GDP & 217 & 101.1 & 233.7 & 0.0 & $1,500.7$ \\
\hline relation new prod. sales / GDP & 279 & 1,109 & 1,119 & 0.0 & 4,393 \\
\hline
\end{tabular}

Source: own analysis

between the vectors of regional scientific publications by SCOPUS classes and regional patent applications by IPC classes. To render the respective thematic profiles mathematically comparable, the two classification systems had to be aligned. To that end, a sample of German authors of scientific publications from the SCOPUS database was matched to inventor names PATSTAT. Homonyms in the names were excluded by a variety of steps as described in (Dornbusch et al. 2013). Based on this author/inventor link, a matrix of publications by IPC classes (3-digit) and 27 SCOPUS fields was generated. From this matrix, the shares of publications by IPC class and field in all publications of the respective field could be retrieved. This share was then used to allocate the regional Chinese publications by fields at the level of IPC classes. Once two matching vectors for scientific and technological profiles are available per province at the level of IPC classes, their cosine similarity could be established according to the standard formula documented below.

The similarity index between regional technological and economic capacities is calculated as the cosine similarity between the vectors of regional patent applications by IPC classes and regional industrial output value by China's standard industrial classification (aligned with, but not fully identical to NACE). Once more, these two classification systems had to be aligned to render the respective thematic profiles mathematically comparable. Here, a similar approach as for the publications was used, however, relying on the link of patent applicants in PATSTAT and firms listed in the firm database ORBIS by Bureau van Dijk. Since there is no NACE class assigned to patent applicants in PATSTAT, the link with ORBIS enables us to gather this information. From there, a matrix of patents by IPC classes and NACE sectors, including shares of IPC classes by sectors was generated. Based on these shares, the regional SIPO filings by IPC classes could be assigned to sectors. To that end, regions' patent output was translated from IPC to industrial classifications, i.e. 2-digit NACE codes. Once two matching vectors for technological and economic profiles are available per province their cosine similarity can be established according to the standard formula documented below.

$$
\cos (\theta)=\frac{\boldsymbol{A}^{\star} \boldsymbol{B}}{\|\boldsymbol{A}\|\|\boldsymbol{B}\|}=\frac{\sum_{i=1}^{n} A_{i} B_{i}}{\sqrt{\sum_{i=1}^{n} A_{i}^{2}} \sqrt{\sum_{i=1}^{n} B_{i}^{2}}}
$$

The further qualifying variables that will be investigated with a view to research question 2 were either taken from official statistics directly or calculated on the basis of variables therein. In a limited number of cases, values for missing years had to be estimated for specific indicators, based on trend extrapolation or pertinent proxies.

Table 1 below displays the descriptive statistics for central relevant variables while Table 2 outlines the correlations between them. The latter underline that all measures consider sufficiently distinct aspects of Chinese provinces' technological portfolios. An exception is the comparatively close correlation between related and unrelated variety, that, however, had equally been found in earlier studies and for conceptual reasons typically not been considered a ground for exclusion (e. g. Castaldi et al. 2015; Boschma et al. 2012). 
Table 2: Corellation between Clustering Variables.

\begin{tabular}{llllll}
\hline & unrelated variety & related variety & LOS-Index (adj.) & cos-sim sci-tech & cos-sim tech-ind \\
\hline unrelated variety & - & & & & \\
related variety & 0.8231 & - & & & \\
LOS-Index (adj.) & -0.6851 & -0.3925 & - & - & - \\
cos-sim sci-tech & 0.3517 & 0.3935 & -0.1072 & 0.0122 & -0.5489 \\
cos-sim tech-ind & 0.4181 & 0.1904 & & & \\
\hline
\end{tabular}

Source: own analysis

\section{Results}

As briefly mentioned in the methodological section, the most stable and meaningful result from the k-means cluster analysis occurred for a pre-specification of seven clusters. As certain specific cases stand for themselves and form single clusters even when the pre-specified number of clusters is notably reduced. Hence, lowering their number from seven to six, for example, leads to a conflation of important main groups into one single cluster of 164 cases, more than half of all observations. At the same time, increasing the number of pre-specified clusters beyond seven results initially mostly in a further fragmentation of already small 'outlier' groups and later in a number of clusters too large to interpret and strong volatility of provincial assignments. Hence, a differentiation into seven clusters must be considered the most robust result.

Before moving to the presentation of the results proper, Figure 2 provides an overview of the different provinces' locations before the concrete findings related to them will be discussed in more detail below.

With a view to Research Question 1, Table 3 displays the euclidical distances between the identified clusters' centers and Table 4 their characteristics with respect to the five (unstandardized) clustering variables. As will be elaborated in detail below, these clusters can be illustratively labelled as leading hubs, techno-industrial drivers, traditional industrial bases, qualified peripheral specializers, remote specializers and the specific case of Tibet as an outpost region.

The first cluster is characterized by limited technological variety in both dimensions, low technological coherence, a poor fit of technological with scientific activities but a good fit of technological activities with the local economy. This cluster of leading hubs includes exclusively Beijing and Guangdong. The second cluster, in contrast, is characterized by high technological variety in both dimensions, limited to low technological coherence and a good local fit between scientific, technological and eco- nomic activities. Continuously, it includes the techno-industrial powerhouses of Shanghai, Jiangsu, Zhejiang, Tianjin, Liaoning, Shandong and Hunan. The third cluster is equally characterized by high technological variety in both dimensions, limited to low technological coherence and a good fit of scientific and technological activities. The local fit of technological activities with the local economy, however, is notably poorer. This cluster includes traditional industrial regions like Hebei, Heilongjiang, Jiangxi, Shaanxi and Shanxi. While the fourth cluster retains high levels of technological related variety, unrelated variety is limited, technological coherence is higher than in other places and technological activities relatively out of sync with both upstream and downstream activities. It includes peripheral regions like Xinjiang, Yunnan, Ningxia, and Inner Mongolia (and a number of others during specific years) that are specialized, yet competent in specific areas. The fifth cluster displays low variety in both dimensions, notable technological coherence, a fit between scientific and technological activities below the second and the third yet slightly better than in the fourth cluster. The local fit of activities in the local economy is worse than in the fourth cluster. This small cluster includes the remote, very specialized regions of Hainan and Qinghai. The remaining two clusters, finally, are expressions of the specific case of Tibet, subsuming two different stages of this outpost region's development across time. In technical terms, they are close to each other but rather distinct from everything else. For purposes of interpretation, they will therefore be subsumed in the following as a single cluster that is characterized by very low technological variety in either dimension, strong technological coherence, a poor fit between scientific and technological efforts and close to none between technological and economic activities.

With a view to Research Question 2, Table 5 displays further characteristics of clusters according to a number of central variables that can be conceptually derived from the above discussion and that have been commonly used in earlier research on regional innovation in China. 


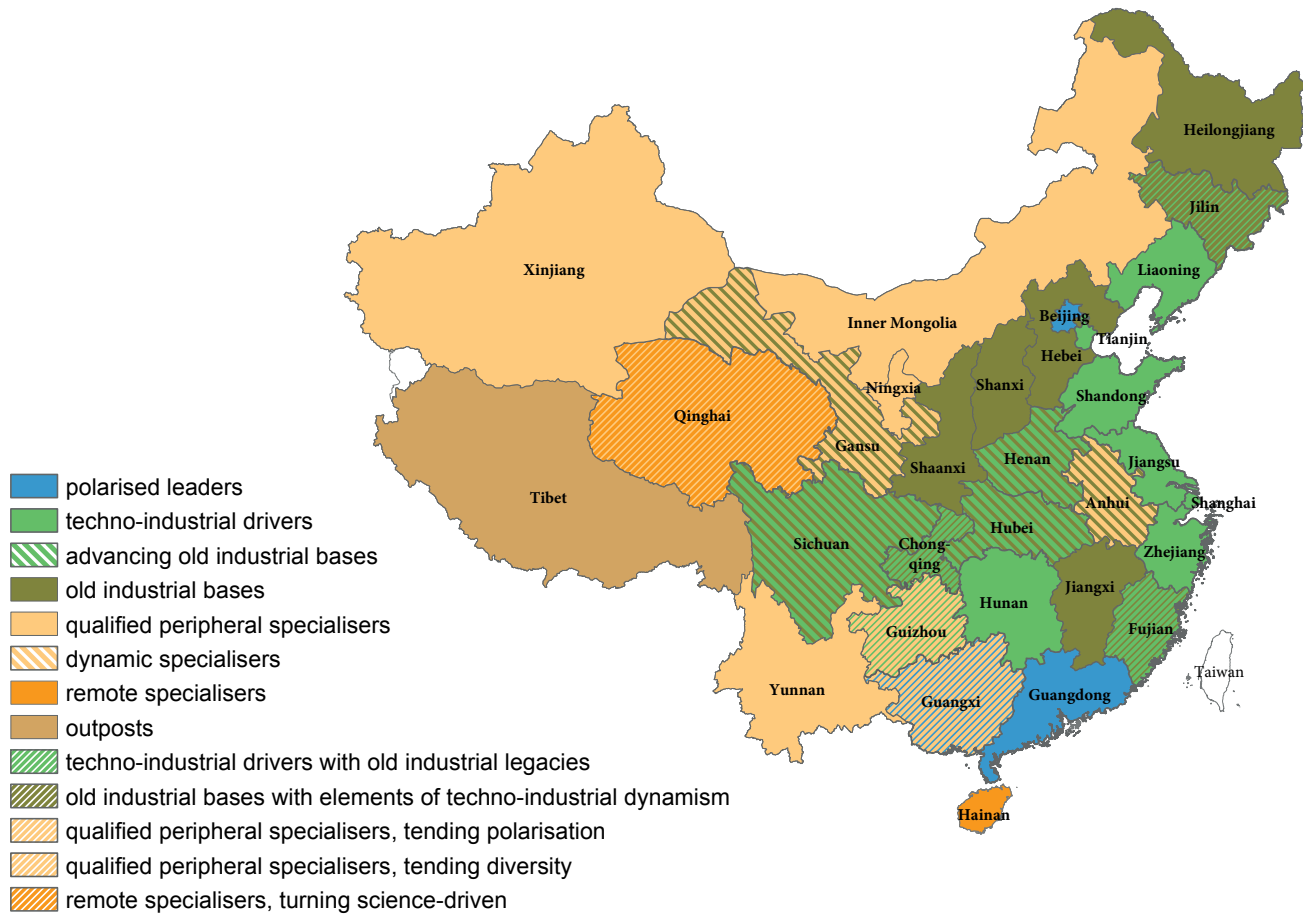

Figure 2: Current Positioning and Trajectories of Provinces. Source: own analysis, Maps based on ESRI ArcMap.
Leading hubs in the first cluster are characterized by the highest levels of GDP per capita but at the same time, the lowest growth rates. They display the by far highest export quotas, high shares of graduates and new product sales per GDP as well as low shares of industries and private R\&D. Techno-industrial drivers in the second cluster are characterized by very high levels of GDP and retain higher growth rates, high export quotas, high shares of graduates and high new product sales per GDP. In this case, however, the share of industry in GDP is second highest among all clusters and the share of private in total R\&D highest reflecting a modern and dynamic industrial sector. Traditional industrial regions in the third cluster are characterized by notably lower levels of GDP, reaching only about half of the level found in the above. Moreover, their recent growth rates remain below average. While the local share of industry is highest among all regions, export orientation and the prevalence of new product sales remain low - indicating limited industrial modernization. Moreover, public R\&D is notably more important than in the above clusters. Qualified peripheral specializers are characterized by levels of GDP comparable to those in the third cluster yet notably - if not fundamentally - higher growth rates. While the share of industry in regional GDP is not far below the levels in the two above clusters, local levels of new product sales and export orientation remain even lower - indicating a situation in which local industries' growth is not yet substantially based on technological development. The role of public $R \& D$ is comparable to that found in traditional industrial regions. Genuinely remote regions, finally, display a markedly lower share of industry in the regional economy, evidencing a rural or pre-industrial state of local economy with limited GDP per capita and low export orientation. In these peripheral areas, a significant if not dominant share of all $R \& D$ is public, and the level of new product sales from local industries very limited to non-existent.

In this light, the above differentiation into clusters enables a classification of different provinces' role in China's overall economy as follows: First, leading hubs: these local economies fulfil important driving roles in China's national innovation system. Local activities in these urbanized locations are embedded at various spatial levels and local ecosystems involved in diverse technological trajectories at the same time. Second, techno-industrial drivers: these regions display evidence of diverse and locally well-integrated regional innovation systems. With their modern(izing) industrial base, they propel China's national economy towards more innovation-driven orientation. Third, traditional industrial bases: these regions display visible signs of technological dynamics and heartening degrees of related variety in the system. However, these dynamics do not yet reach an established industrial basis with limited innovative activities. Fourth, qualified peripheral specializers: technological activities in these regions are more specialized, yet related variety remains high. The regional fit of these thematically focused dynamics with surrounding activities, however, remains poor on 
Table 3: Distances between the Cluster's Centres.

\begin{tabular}{llllllll}
\hline & Cluster 1 & Cluster 2 & Cluster 3 & Cluster 4 & Cluster 5 & Cluster 6a & Cluster 6b \\
\hline Cluster 1 & & 3.394 & 3.964 & 3.394 & 3.983 & 7.459 & 6.947 \\
Cluster 2 & 3.394 & & 1.573 & 2.564 & 3.719 & 7.768 & 7.975 \\
Cluster 3 & 3.964 & 1.573 & & 1.950 & 3.170 & 7.282 & 7.467 \\
Cluster 4 & 3.394 & 2.564 & 1.950 & & 2.321 & 5.936 & 6.181 \\
Cluster 5 & 3.983 & 3.719 & 3.170 & 2.321 & & 4.348 & 4.393 \\
Cluster 6a & 7.459 & 7.768 & 7.282 & 5.936 & 4.348 & & 2.513 \\
Cluster 6b & 6.947 & 7.975 & 7.467 & 6.181 & 4.393 & 2.513 & \\
\hline
\end{tabular}

Source: own analysis.

Table 4: Clusters based on Technological Portfolios.

\begin{tabular}{|c|c|c|c|c|c|}
\hline cluster type & $\begin{array}{l}\text { unrelated } \\
\text { variety }\end{array}$ & related variety & $\begin{array}{l}\text { LOS-Index } \\
\text { (adj.) } \\
\star 100,000\end{array}$ & $\begin{array}{l}\text { cos-sim } \\
\text { sci-tech }\end{array}$ & $\begin{array}{l}\text { cos-sim } \\
\text { tech-ind }\end{array}$ \\
\hline $\begin{array}{l}\text { C1: leading hubs } \\
\text { limited variety, low coherence, } \\
\text { poor fit with science, good fit with economy }\end{array}$ & 2.50 & 2.32 & 337 & 0.51 & 0.76 \\
\hline $\begin{array}{l}\text { C2: techno-industrial drivers } \\
\text { high variety, limited-low coherence, } \\
\text { good fit with both science \& economy }\end{array}$ & 2.72 & 2.73 & 472 & 0.79 & 0.70 \\
\hline $\begin{array}{l}\text { C3: traditional industrial bases } \\
\text { high variety, limited-low coherence, good fit in science, } \\
\text { poor fit with economy }\end{array}$ & 2.68 & 2.74 & 495 & 0.81 & 0.41 \\
\hline $\begin{array}{l}\text { C4: qualified peripheral specializers } \\
\text { high related, limited unrelated variety, notable coher- } \\
\text { ence, limited fit either direction }\end{array}$ & 2.50 & 2.63 & 658 & 0.66 & 0.40 \\
\hline $\begin{array}{l}\text { C5: remote specializers } \\
\text { low variety, notable coherence, } \\
\text { moderate fit in science, poor fit in economy }\end{array}$ & 2.17 & 2.20 & 664 & 0.75 & 0.37 \\
\hline $\begin{array}{l}\text { C6: outposts } \\
\text { very low variety, strong coherence, } \\
\text { poor fit with science, none with economy }\end{array}$ & 1.53 & 1.72 & 1,054 & 0.66 & 0.22 \\
\hline
\end{tabular}

Source: own analysis.

aggregate. Fifth, remote specializers: in these peripheries, technological activities are very specialized and the local fit of technological and economy activities very poor. The data suggest that many technological outcomes reflect scientific rather than economic efforts. Sixth, outposts: while scientific, technological and economic activities develop dynamically, they do so in a disconnected manner. While these analyses are based on de facto situations in provinces, the clusters as such describe functions. Hence, provinces' attribution can change over time - as will be outlined in the following.

With a view to Research Question 3, there are two central findings (cf. Table 6). First, that a number of provinces are moving away from a set-up as traditional, rather stagnant, industrial bases towards a different configura- tion and, second, that the end of this development need not necessarily be the same. Improving the local match between technological and economic activities, Hubei's, Henan's and Sichuan's configuration, evolved towards that of better-performing, high-income techno-industrial drivers. Others, like Gansu and Anhui embarked onto a more focused, specialization-oriented trajectory leading them into a group with lower per capita incomes - which was in parallel joined by peripheral regions like Guizhou or Guangxi. 
Table 5: Characteristics of Clusters.

\begin{tabular}{|c|c|c|c|c|c|c|c|}
\hline cluster type & $\begin{array}{l}\text { GDP } \\
\text { per pop. }\end{array}$ & $\begin{array}{l}\text { growth GDP } \\
\text { per pop. }\end{array}$ & $\begin{array}{l}\text { share } \\
\text { public R\&D }\end{array}$ & $\begin{array}{l}\text { share } \\
\text { industry } \\
\text { in GDP }\end{array}$ & $\begin{array}{l}\text { ratio export } \\
\text { per GDP }\end{array}$ & $\begin{array}{l}\text { new } \\
\text { products } \\
\text { per GDP }\end{array}$ & $\begin{array}{l}\text { graduates } \\
\text { per pop }\end{array}$ \\
\hline C1: leading hubs & 6.985 & $8.9 \%$ & 0.318 & 0.352 & 636.5 & 1,759 & 57.60 \\
\hline C2: techno-industrial drivers & 5.713 & $11.6 \%$ & 0.175 & 0.487 & 380.0 & 1,918 & 55.30 \\
\hline C3: traditional industrial bases & 3.118 & $10.9 \%$ & 0.271 & 0.507 & 101.9 & 760 & 49.37 \\
\hline C4: qualified peripheral specializers & 3.260 & $13.2 \%$ & 0.250 & 0.469 & 83.0 & 611 & 34.27 \\
\hline C5: remote specializers & 3.504 & $16.7 \%$ & 0.358 & 0.369 & 74.2 & 190 & 39.12 \\
\hline C6: outposts & 1.805 & $13.4 \%$ & 0.657 & 0.324 & 104.9 & 30 & 26.90 \\
\hline
\end{tabular}

Source: own analysis.

Table 6: Movements of Provinces between Groups.

\begin{tabular}{|c|c|}
\hline cluster type & province \\
\hline C1: leading hubs & Beijing, Guangdong \\
\hline C2: techno-industrial drivers & $\begin{array}{l}\text { Shanghai, Jiangsu, Zhejiang, Tianjin, Liaoning, Shandong, Hunan, } \\
\text { (Chongqing, Fujian) }\end{array}$ \\
\hline C3: traditional industrial bases & Hebei, Heilongjiang, Jiangxi, Shaanxi, Shanxi, (Jilin) \\
\hline C4: qualified peripheral specializers & Xinjiang, Yunnan, Ningxia, Inner Mongolia, (Guizhou, Guangxi) \\
\hline C5: remote specializers & Hainan, (Qinghai) \\
\hline C6: outposts & Tibet \\
\hline $\begin{array}{l}\text { advancing old industrial bases: } \\
\text { transition from traditional industry to techno-industrial drivers }\end{array}$ & Hubei, Henan, Sichuan \\
\hline $\begin{array}{l}\text { dynamic specializers: } \\
\text { transition from traditional industry to qualified specialization }\end{array}$ & Gansu, Anhui \\
\hline
\end{tabular}

Note: Provinces in brackets tend or have tended towards other groups without, however, a clear trend.

Source: own analysis.

\section{Discussion}

This discussion section will discuss this study's specific findings in relation to existing studies on China while the subsequent summary and conclusions section will expand on its more generic conceptual and methodological implications.

A first specific finding that surprises is that China's leading hubs display a more limited degree of overt specialization than existing literature on their past trajectories would suggest (cf. Liefner and Wei 2014; Fu et al. 2012; Kroll and Schiller 2010; Wang et al. 2010; Segal 2003). Again different from what some recent sources (Guo and He 2017) put forward, aggregate related variety remains low in these hubs. In the authors' view, these findings underscore the need to conceive of technological specialization as a multi-scalar process with diverse facets. Most likely, both Beijing and Guangdong are anchor-areas for various global innovation chains (Coe and Yeung 2015; Wei 2014) so that, in either case, aggregate statistics will reflect a broad conglomerate of various partial strands of activity that neither create dominant specializations, nor localized industrial dynamics, which would give rise to specifically high levels of related variety. At the same time, a good match between technology and economy evidences that both constitute dynamic regional economies in which few economically relevant actors are disengaged from the innovation process. Finally, a poor match of scientific and technological activities reflects that Beijing's science system serves the entire country through its designated role as national hub of science and technology (Fan and Chen 2014) while that in Guangdong remains emerging, not yet having synchronized with the region's industrial research and development capacities (Frietsch and Kroll 2014).

The findings on the second and third cluster, on the contrary, do not fundamentally surprise. As existing research suggests, vibrant technological clusters have developed in China's coastal innovation systems of which this paper now finds supportive evidence (He et al. 2018; 
He and Zhu 2018; Guo and He 2018; Liu et al. 2018; Zhou et al. 2016; Kroll and Frietsch 2014; Liefner and Wei 2014; Liefner et al. 2013). At the same time, it does not surprise to find pervasive legacies of notable science-economy disconnect in China's old industrial regions (Liefner and Wei 2014; Kroll and Liefner 2008; Fan 1995). Interestingly, both groups do not differ much with a view to technological variety or local science-technology fit - which seems well developed in both. Apparently, it is primarily the better integration of technological and economic activity that elevates regions into a better performing group - arguably, as it allows them to better leverage their technological capacities for actual innovation.

At the same time, the analysis supports that catching-up processes and the institutional transformation of economic systems (Liu et al. 2018; Kroll 2016) leave their traces not only in the configuration of provinces' technological portfolios' but, most importantly, in the local fit between technological and economy activity.

Furthermore, the findings provide interesting insights into the characteristics of a generally less studied group of Chinese regions whose trajectory remains distinct from both today's leading regions and those converging to it. While technological activities in them are generally more fragmented, focused and, on average, poorly connected with the regional economy, a certain level of related variety provides evidence of emerging focused dynamics and possible "pockets of excellence" in the periphery. Notably, the overall poor match between technological activities and the surrounding subsystems does not rule out that there could indeed be a connection to some domains of the local economy - which would in most cases not affect aggregate figures sufficiently. To some extent, moreover, the comparatively good local fit between science and technology evokes the image of scientific institutions sustaining small growth poles. If what holds for Europe also holds for China, such initially limited sources of variety could become relevant for the future development of lagging regions (cf. Xiao et al. 2018), even if, as this study found, they lead them less directly into a high-income group. Academically, this idea has so far mostly been discussed in the European literature (e.g. Reid et al. 2015), whereas in China, it is more often mentioned informally. During late 2018 , however, one of the authors was able to validate this section's interpretation during interviews with universities and science parks in Yunnan. Evidently, government is investing great efforts into building capacities in these regions, while, at the same time, their connectivity to the local economy remains partial and thematically specific.

With respect to the genuine periphery, finally, it is interesting to note how clearly Tibet remains distinct with respect to its configuration of scientific, technological and economic activities, which are, with great likelihood, each in their own way initiated, maintained and directed from outside the region - and thus inevitably appear disconnected when analyzed through a local lens. Hainan and Qinghai, on the contrary, display a technological portfolio with low levels of technological variety but at the same time, an alignment of scientific and technological activities higher than that in the fourth cluster. A high role of public research suggests that activities in the local technological system may be primarily driven by intentionally created poles of dynamism in public research. Overall, however, such non-industrial peripheries that are sustained by public science dynamics remain rare and a somewhat atypical set-up.

In summary, the findings underline the substantial and growing momentum of China's recent 'technological turn' and the fundamental impact that it is about to develop on that country's geographies of innovation. It underlines that - beyond the developed coastal rim various regions of the old industrial belt are join the nation's broadening group of techno-industrial drivers by improving their match between technological and economic activities. At the same time, a number of provinces develops a contrasting inclination towards the development of specific, locally disconnected focal areas of development, driven by either industry or science. Typically, this happens in regions with higher growth rates, whose economies, however, are by and large not yet based on technology-driven development. As confirmed by anecdotal evidence, these technological activities might at least partially be an uncoordinated reflex to investment options resulting from increased prosperity. In these times of transition, this cautions against a direct translation of insights gained in coastal locations to interior provinces - which may still lead to an overestimation of real dynamics.

\section{Summary and Conclusion}

Beyond advancing our understanding of China's geographies of innovation, this study has some more general implications that will be summarized below.

From a conceptual perspective, it suggests that what the existing literature promotes as an ideal-typical, desirable configuration of regional technological portfolios is in fact not too distinct from what we begin to observe in China's leading regions. As has been found for established market economies, economic and innovative dynamism in China are associated with (even if not necessarily 
caused by) high levels of related variety in the technological domain. At the same time, the analysis suggests that access to matching upstream and downstream activities in science and industry can be a more decisive discriminatory factor between successful and less successful regions during times of catch-up and transition and that focuse dynamics around related variety alone do not yet lead regions onto a higher-income growth path. Analytically, the paper refrained from asserting and testing specific causalities - which remains for later research to address. Instead, it has worked towards clarifying the context-specificity of common assumptions on the role of variety in regional technological portfolios. It has emphasized that, depending on circumstances their relation to growth may be contingent on and superimposed by other factors. Relating our findings to existing, country-specific literature, the above discussion section has provided insights into what this means in concrete terms.

Methodologically, our analyses thus suggest that future studies under equally distinct framework conditions will have to ascertain ceteris paribus conditions very carefully or, much better, to make relevant additional aspects an integral part of their analysis in the first place. Even if common assumptions on the role of technological relatedness hold unabated in an abstract sense, future studies should move towards including additional factors of local contingency - at least when considering variety in the technological domain. Only thus can they expect to satisfactorily explain the dynamics of national economic systems that are - at different levels - less in equilibrium than Western European ones. With a view to recent findings on Europe's peripheral regions (Kroll, 2018; Isaksen and Trippl, 2017), this may already apply to much work covering the entire European Union but, more clearly, to any contribution towards explaining local manifestations or origins of regional development in China.

In light of the above said, this paper constitutes a first step towards identifying the full set of driving forces behind the internal, spatial re-organization of an economy that is about to reshape global geographies of innovation. Conscious of the overall setting documented and explained in this paper, future research will have to move closer towards establishing concrete causalities and explore specific factors in more detail. Furthermore, it would be rewarding to repeat the same exercise in a few years' time to assess whether China's overall geographies of innovation have continued to evolve along the paths observable today - or whether new trajectories of development have emerged among either leading or lagging regions.

Funding: Deutsche Forschungsgemeinschaft KR 4895/2-1

\section{References}

Asheim, B. T. 2012. The Changing Role of Learning Regions in the Globalising Knowledge Economy: A Theoretical Re-Examination'. Regional Studies 46(3):993-1004.

Asheim, B. T., and Gertler, M. S. 2005. "The geography of innovation: regional innovation systems". In The Oxford Handbook of Innovation, Edited by: Fagerberg, J., Mowery, D. and Nelson, R. 291-317. Oxford: Oxford University Press

Asheim, B., and Coenen, L. 2006. Contextualising Regional innovation Systems in a Globalising Learning Economy: On Knowledge Bases and Institutional Frameworks. Journal of Technology Transfer 31:163-173.

Asheim, B., Grillitsch, M., and Trippl, M. 2016. Regional innovation systems: Past - present - future. In Handbook on the Geographies of Innovation, ed. R. Shearmur, C. Carrincazeaux, and D. Doloreux, 45-62. Cheltenham: Edward Elgar. doi: $10.4337 / 9781784710774$

Asheim, B., and Isaksen, A. 2002. Regional Innovation Systems: The Integration of Local 'Sticky' and Global 'Ubiquitous' Knowledge. The Journal of Technology Transfer 27(1):77-86.

Barbieri, E., Di Tommaso, M. R., and Bonnini, S. 2012. Industrial development policies and performances in Southern China: Beyond the specialized industrial cluster program. China Economic Review 23(3):613-625. doi: 10.1016/j. chieco.2010.12.005

Bathelt, H., Malmberg, A., and Maskell, P. 2004. Clusters and knowledge: Local buzz, global pipelines and the process of knowledge creation. Progress in Human Geography 28(1):31-56.

Boschma, R. 2017. Relatedness as driver of regional diversification: a research agenda. Regional Studies 51(3):351-364. doi: 10.1080/00343404.2016.1254767

Boschma, R., Coenen, L., Frenken, K., Truffer, B. 2017. Towards a theory of regional diversification: combining insights from evolutionary economic geography and transition studies, Regional Studies, 51,1: 31-45.

Boschma, R., Minondo, A., and Navarro, M. 2012. Related variety and regional growth in Spain. Papers in Regional Science 91(2):241-256, https://doi.org/10.1111/j.14355957.2011.00387.x

Boschma, R.A. 2005. Proximity and innovation: A critical assessment. Regional Studies 39(1):61-74. doi: $10.1080 / 0034340052000320887$

Capello, R., and Kroll, H. 2016. From theory to practice in smart specialization strategy: emerging limits and possible future trajectories. European Planning Studies 24: 1393-1406. doi:10. 1080/09654313.2016.1156058

Castaldi, C., Frenken, K., and Los, B. 2015. Related Variety, Unrelated Variety and Technological Breakthroughs: An analysis of US State-Level Patenting. Regional Studies 49(5):767-781,http:// dx.doi.org/10.1080/00343404.2014.940305

Coe, N. M., and Yeung, H. W.-C. 2015. Global production networks: Theorizing economic development in an interconnected world Global Production Networks: Theorizing Economic Development in an Interconnected World. Oxford: Oxford University Press.

Content, J., and Frenken, K. 2016. Related variety and economic development: a literature review. European Planning Studies 24(12):2097-2112 
Cooke, P. 1992. Regional innovation systems: competitive regulation in the new Europe. GeoForum 23:365-382.

Cooke, P. 1998. Introduction. Origins of the concept. In Regional Innovation Systems, ed. H.J. Braczyk, Cooke, P., and Heidenreich, M. 1998, 2-25. London: UCL Press.

Cooke, P., Heidenreich, M., and Bracyck, H. J. 1998. Regional innovation systems: The role of governance in a globalised world. London: Routledge

David, P. A., Foray, D., Dalle, J. N. 1998. Marshallian externalities and the emergence and spatial stability of technological enclaves. Economics of Innovation and New Technologies 6(2-3):147-182.

Dornbusch, F., and Schmoch, U., Schulze, N., Bethke, N. 2013. Identification of university-based patents: A new large-scale approach. Research Evaluation 22(1):52-63.

Edquist, C. 1997. Systems of Innovation: Technologies, Institutions, and Organizations. London Pinter.

Fan, C. C. 1995. Of belts and ladders: State policy and uneven regional development in post-Mao China Annals of the Association of American Geographers 85(3):421-449.

Fan, J., and Chen, D. 2014. Technological Advantage of Beijing and its Effect on Urban Development. In Innovation and Regional Development in China, ed. Liefner, I., and Wei.Y. D. London: Routledge.

Foray, D. (Hg.) 2014. Smart specialization. Opportunities and challenges for regional innovation policy. London[etc.]: Routledge Taylor \& Francis Group.

Freeman, C. 1987. Technology Policy and Economic Performance: Lessons from Japan. London: Pinter

Frenken, K., and Boschma, R. A. 2007. A theoretical framework for evolutionary economic geography: industrial dynamics and urban growth as a branching process. Journal of Economic Geography 7:635-649.

Frenken, K., Van Oort, F., and Verburg, T. 2007. Related variety, unrelated variety and regional economic growth. Regional Studies 41(5):685-697. doi: 10.1080/00343400601120296

Frietsch, R., and Schmoch, U., 2010. Transnational Patents and International Markets. Scientometrics 82(1):185-200.

Fu, W., Revilla Diez, J., and Schiller, D. 2012. Interactive Learning, Informal Networks and Innovation: Evidence from Electronics Firm Survey in the Pearl River Delta, China. Research Policy 42: 635-646. DOI: 10.1016/j.respol.2012.09.006

Grillitsch, M., Asheim, B., and Trippl, M. 2018. Unrelated knowledge combinations: The unexplored potential for regional industrial path development Cambridge. Journal of Regions, Economy and Society 11(2):257-274.

Grupp, H. 1998. Foundations of the Economics of Innovation Theory, Measurement and Practice. Cheltenham: Edward Elgar.

Gu, S. 1999. China's Industrial Technology: Market Reform and Organisational Change. London: Routledge.

Guo, Q., He, C., \& Li, D. 2015. Entrepreneurship in China: The role of localisation and urbanisation economies. Urban Studies 47(1): 121-144 https://doi.org/10.1177/0042098015595598

Guo, Q., and He, C. 2017. Production space and regional industrial evolution in China. GeoJournal 82(2):379-396.

He, C., Guo, Q., Rigby, D. 2015. Industry Relatedness, Agglomeration Externalities and Firm Survival in China. Papers in Evolutionary Economic Geography \# 15.28, http://econ.geo.uu.nl/peeg/ peeg1528.pdf
He, C., and., Zhu, S. 2018. Evolution of Export Product Space in China: Technological Relatedness, National/Local Governance and Regional Industrial Diversification. Tijdschrift voor economische en sociale geografie 109(4):575-593, https://doi. org/10.1111/tesg.12309

He, C., Yan, Y., and Rigby, D. 2018. Regional industrial evolution in China. Papers in Regional Science 97(2):173-198

Hidalgo, C. A., Klinger, B., Barabasi, A. L., \& Hausmann, R. 2007. The product space conditions the development of nations. Science, 317, 482-487. doi:10.1126/science. 1144581

Isaksen, A. 2015. Industrial development in thin regions: Trapped in path extension? Journal of Economic Geography 15(3):585-600. doi: $10.1093 /$ jeg/lbu026

Isaksen, A., and Trippl, M. 2017. Exogenously Led and PolicySupported New Path Development in Peripheral Regions: Analytical and Synthetic Routes. Economic Geography 93(5):436-457.

Isaksen, A., and Trippl, M. 2016. Path development in different regional innovation systems: A conceptual analysis. In Innovation Drivers and Regional Innovation Strategies, ed. Davide Parrilli, M., Dahl Fitjar,R., and Rodriguez-Pose, A., 66-84. London: Taylor \& Francis. doi: 10.4324/9781315671475

Kline, S. J., and Rosenberg, N. 1986. An overview of innovation. In The Positive Sum Strategy: Harnessing Technology for Economic Growth, ed. Landau R., and Rosenberg, N.: 275-305 Washington, D.C.: National Academy Press.

Kroll, H. 2016. Exploring pathways of regional technological development in China through patent analysis. World Patent Information 46: 74-86

Kroll, H. 2018. Smart Specialisation in Economically and Institutionally Less Favoured Regions. In Strategic Approaches to Regional Development: Smart Experimentation in Less-Favoured, ed. Kristensen, I., Dubois, A., and Teräs, J. (in print): Oxford: Routledge.

Kroll, H., and Frietsch, R. 2014. Regional Structures and Trends in China's Innovation System: An Indicator-Based Account of the Last Decade's Developments. In Innovation and Regional Development in China: 41-72, ed. Liefner, I., and Wei, Y.D. New York, London: Routledge.

Kroll, H., and Liefner, I., 2008. Spin-off enterprises as a means of technology commercialisation in a transforming economy - Evidence from three universities in China. Technovation 28(5):298-313.

Kroll, H., and Schiller, D. 2010. Establishing an interface between public sector applied research and the Chinese enterprise sector: Preparing for 2020. Technovation 20(2).

Leydesdorff, L., and Zeng, G. 2001. University-industry-government relations in China. An emerging national system of innovations. Industry and Higher Education 15:179-182.

Liefner, I. 2014. Explaining regional development and innovation in China: how much can we learn from applying established Western theories. In Innovation and Regional Development in China, ed. Liefner, I., and Wei, Y. D. New York, London: Routledge.

Liefner, I., and Wei, Y. D. 2014. Innovation and Regional Development in China. New York, London: Routledge.

Liefner, I., Wei, Y. H. D., and Zeng, G., 2013: The innovativeness and heterogeneity of foreign-invested high-tech companies in Shanghai. Growth \& Change 44(3):522-549 
Liu, H., and Jiang, Y. 2001: Technology transfer from higher education institutions to industry in China: nature and implications. Technovation 21, 175-188.

Liu, X, and White, S. 2001. Comparing innovation systems: a framework and application to China's transitional context. Research Policy 30(7):1091-1114.

Liu, X., Gao, T., and Wang, X. 2018. Regional Innovation Index of China: 2017: How Frontier Regions Innovate. Singapore:Springer Nature.

Lundvall, B-Å. (ed.) 1992. National Innovation Systems: Towards a Theory of Innovation and Interactive Learning. London: Pinter.

Markusen, A 1996. Sticky Places in Slippery Space: A Typology of Industrial Districts. Economic Geography 72(3):293-313

Martin, R., and Sunley, P. 2006. Path dependence and regional economic evolution. Journal of Economic Geography 6(4):395-437.

Neffke, F., Henning, M., and Boschma, R. 2011. How Do Regions Diversify over Time? Industry Relatedness and the Development of New Growth Paths in Regions. Economic Geography 87:237-265.

Plekhanov, D. 2017. Quality of China's Official Statistics: A Brief Review of Academic Perspectives Copenhagen Journal of Asian Studies 35(1):76.

Radosevic, S. 1998. National Systems of Innovation in Economies of Transition: Between Restructuring and Erosion. Industrial and Corporate Change 7, 1, 77-108.

Reid, A., Markianidou, P., and Evrigenis, A. 2015. Pockets of excellence with innovation potential. A study for the European Commission DG Research \& Innovation. EUR 27900 EN. European Commission, Brussels. https://ec.europa.eu/ research/openvision/pdf/rise/030616_pockets_of_excellence. pdf
Segal, A. 2003. Digital Dragon: High-Technology Enterprises in China. Ithaca, Cornell University Press.

Si, Y. F., Liefner, I., and Wang, T., 2013. Foreign direct investment with Chinese characteristics: A middle path between Ownership-Location-Internalization model and LinkageLeverage-Learning model. Chinese Geographical Science 23(5):594-606

Storper M., and Walker, R. 1989. The Capitalist Imperative: Territory, Technology and Industrial Growth. Oxford: Blackwell.

Wang, C., Lin, G., and Li, G. 2010. Industrial clustering and technological innovation in China: New evidence from the ICT industry in Shenzhen. Environment and Planning A 42:1987-2010. doi: $10.1068 /$ a 4356 .

Wei, Y. D. 2014. FDI networks, R\&D activities and the making of global cities in China. In Innovation and Regional Development in China, 97-120, ed. Liefner, I., and Wei, Y.D. New York, London: Routledge.

Xiao, J., Boschma, R., and Andersson, M. 2018. Industrial Diversification in Europe: The Differentiated Role of Relatedness. Economic Geography 94(5):514-549, doi: 10.1080/00130095.2018.1444989

Yeung, H. 2009. Transnationalizing entrepreneurship: a critical agenda for economic geography. Progress in Human Geography 33:210-235.

Zhang, J. 2013 Related Variety, Global Connectivity and Institutional Embeddedness: Internet Development in Beijing and Shanghai Compared. Regional Studies 47(7):1065-1081. doi: 10.1080/00343404.2011.622744

Zhou, Y., Lazonick, W., and Sun, Y. (eds.) 2016. China as an Innovation Nation. Oxford, Oxford University Press. 